\title{
Performance of the White method for estimating groundwater evapotranspiration under conditions of deep and fluctuating groundwater
}

\author{
Pei Zhang, ${ }^{1,2}$ Guofu Yuan, ${ }^{1 *}$ Ming-an Shao, ${ }^{1 *}$ Xiaobo $\mathrm{Yi}^{3}$ and Tao $\mathrm{Du}^{1,2}$ \\ ${ }^{1}$ Key Laboratory of Ecosystem Network Observation and Modeling, Institute of Geographical Sciences and Natural Resources Research, Chinese \\ Academy of Sciences, Beijing 100101, China \\ ${ }^{2}$ University of Chinese Academy of Sciences, Beijing 100049, China \\ ${ }^{3}$ College of Natural Resources and Environments, Northwest A\&F University, Yangling 712100, China
}

\begin{abstract}
:
The White method is a simple but the most frequently applied approach to estimate groundwater evapotranspiration $\left(E T_{\mathrm{g}}\right)$ from groundwater level diurnal signals. Because of a lack of direct measurements of $E T_{\mathrm{g}}$, it is difficult to evaluate the performance of the White method, particularly in field environments with variable groundwater fluctuations. A 2-year field observation in a hyper-arid riparian tamarisk (Tamarix spp.) stand with deep groundwater depth in the lower Tarim River basin of China was conducted to measure the surface evapotranspiration $\left(E T_{\mathrm{s}}\right)$ and groundwater table. The performance of the White method and the influences of the variable groundwater fluctuations on the determinations of the specific yield $\left(S_{\mathrm{y}}\right)$ and recharge rate of groundwater $(r)$ in the White method were investigated. The results showed that the readily available $S_{\mathrm{y}}$ determined by Loheide's method was feasible but must be finely determined based on the soil textures in the layers in which the groundwater level fluctuated. A constant $S_{\mathrm{y}}$ value for a defined porous medium could be assumed regardless of the discharge or recharge processes of groundwater. The time span of $0000 \mathrm{~h}$ to $0600 \mathrm{~h}$ for $r$ estimation for the White method worked best than other time spans. A 2-day moving average of $r$ values further enhance $E T_{\mathrm{g}}$ estimation. Slight effects of environmental or anthropogenic disturbances on the diurnal fluctuations of groundwater level did not influence the $E T_{\mathrm{g}}$ estimations by the White method. Our results provide valuable references to the application of the White method for estimating daily $E T_{\mathrm{g}}$ in desert riparian forests with deep groundwater depth. Copyright $\odot 2015$ John Wiley \& Sons, Ltd.
\end{abstract}

KEY WORDS groundwater evapotranspiration; the White method; specific yield; recharge rate of groundwater; desert riparian forest; deep groundwater depth

Received 12 March 2015; Accepted 24 May 2015

\section{INTRODUCTION}

In arid and semiarid climates, groundwater is the main and most reliable source of water for ecosystems, particularly for ecosystems dominated by phreatophytes (Orellana et al., 2012). Groundwater evapotranspiration $\left(E T_{\mathrm{g}}\right)$ is a critical resource management issue, and its estimation has been studied extensively (Lubczynski, 2009). $E T_{\mathrm{g}}$ refers to water losses from groundwater in both forms of evapotranspiration: (1) direct water uptake through roots from groundwater or the capillary fringe and (2) direct evaporation of water from the water table, which is then transported through the unsaturated zone to the land surface in the vapour phase (Ridolfi et al., 2008; Vervoort and van der Zee, 2009; Orellana et al., 2012).

*Correspondence to: Guofu Yuan and Ming-an Shao, Key Laboratory of Ecosystem Network Observation and Modeling, Institute of Geographical Sciences and Natural Resources Research, Chinese Academy of Sciences, Beijing 100101, China.

E-mail: yuangf@igsnrr.ac.cn;shaoma@igsnrr.ac.cn
Many studies have attempted to quantify $E T_{\mathrm{g}}$ based on the groundwater level diurnal variations. Among these methods, the White method (White, 1932) is one of the most common approaches for quantifying $E T_{\mathrm{g}}$ because of its simplicity (Martinet et al., 2009; Yin et al., 2013). The White method is expressed by the following equation:

$$
E T_{\mathrm{g}}=(24 r \pm s) \times S_{\mathrm{y}}
$$

The daily $E T_{\mathrm{g}}$ is equal to the sum of the storage change $\left(s, \mathrm{~mm} \mathrm{~d}^{-1}\right)$ plus groundwater recharge $\left(r, \mathrm{~mm} \mathrm{~h}^{-1}\right)$. The former is represented by the variation of the groundwater table, while the latter is derived from the water level behaviour at night. Both quantities are multiplied by the specific yield $\left(S_{\mathrm{y}}, \mathrm{cm}^{3} \mathrm{~cm}^{-3}\right)$, which serves as a conversion factor (Fahle and Dietrich, 2014). The White method estimates daily $E T_{\mathrm{g}}$ using hourly or more frequent data on groundwater levels from a monitoring well. Moreover, the White method provides the basis for all subsequent $E T_{\mathrm{g}}$ estimation algorithms from the 
groundwater level diurnal signals. Most of these methods are based on the same fundamental principle and encompass three components: specific yield, recharge rate, and storage change (Dolan et al., 1984; Gribovszki et al., 2008; Loheide, 2008; Hatler and Hart, 2009).

$S_{\mathrm{y}}$ is of crucial importance because errors in $S_{\mathrm{y}}$ estimation directly translate to the $E T_{\mathrm{g}}$ estimates (Loheide et al., 2005; Lautz, 2008; Mould et al., 2010; Cheng et al., 2013). However, there are many difficulties in estimating $S_{\mathrm{y}}$ because this parameter is not constant with time; it depends upon the water table depth and the soil hydraulic properties. It is also influenced by hysteresis and differs if the water table is in discharge or recharge (Alley et al., 2002; Scanlon et al., 2002; Nachabe et al., 2005). $S_{\mathrm{y}}$ is often calculated for water table drainage only, but for a rising water table condition, the encapsulated air is likely to reduce the value of $S_{\mathrm{y}}$, that is, less water volume is needed to provide a positive water table fluctuation (water table rise) than a negative fluctuation (water table drop) (Nachabe et al., 2005). In addition, the basic assumption of the White method about the recharge rate $(r)$, namely, that the average rate of groundwater level rise between midnight and $0400 \mathrm{~h}$ is equal to the average groundwater recharge rate over the entire day, is not appropriate for variable groundwater fluctuations. The recharge rate is often a function of the head difference between the observation well and the recharge source (Loheide, 2008). The transient recharge rate would change with time. The replacement of the daily average recharge rate with that determined during a certain time span induces errors in the estimation of $E T_{\mathrm{g}}$ (Fahle and Dietrich, 2014). Consequently, the White method is usually modified with regard to the time period used for recharge estimation (Rushton, 1996; Loheide, 2008; Miller et al., 2010). Some other methods even avoid using the variable $r$ (Soylu et al., 2012; Wang and Pozdniakov, 2014).

The variables $S_{\mathrm{y}}$ and $r$ in the White method are timedependent, and the time dependence of $S_{\mathrm{y}}$ and $r$ usually results from the variable water level fluctuations with time, as mentioned earlier. In field environments, climate variability, plant growth, river level changes, and anthropogenic disturbance might influence the temporal processes of shallow groundwater level fluctuations, which would reduce the $E T_{\mathrm{g}}$ estimation precision of the White method (Zhu et al., 2011). Because of the difficulty in directly measuring $E T_{\mathrm{g}}$, it is difficult to evaluate the influences of the $S_{\mathrm{y}}$ and $r$ estimations on the performance of the White method in field environments. Some evaluations have been conducted based on groundwater flow modelling (Loheide et al., 2005; Yin et al., 2013). Recently, from direct measurements of $E T_{\mathrm{g}}$ and $r$ obtained with a lysimeter, Fahle and Dietrich (2014) compared six methods of estimating $E T_{\mathrm{g}}$ using diurnal groundwater level fluctuations and evaluated the role and influences of $S_{\mathrm{y}}$ and $r$ in these methods. However, his experiment was conducted over a grassland site with a shallow groundwater table. The conclusions about the different methods could be notably different for a deeper groundwater table (Fahle and Dietrich, 2014), which is common across riparian forests in arid regions. Moreover, the seasonal processes of $E T_{\mathrm{g}}$ under variable water level fluctuations due to complex environmental changes could not be reproduced in a lysimeter-based experiment. Therefore, an evaluation of the White method under conditions with deep groundwater level and different water level fluctuations in the field and natural environment is necessary.

The Tarim Basin is located in a hyper-arid hinterland area of the Eurasian continent. The Tarim River, which crosses the basin, is an inland river with a length of $1321 \mathrm{~km}$. A narrow desert riparian forests ecosystem develops along the river. Tamarisk (Tamarix spp.) is one of two constructive species in the riparian ecosystem. It is a typical phreatophytic and groundwater-dependent species in this area (Xu and $\mathrm{Li}, 2006)$. The surface evapotranspiration $\left(E T_{\mathrm{s}}\right)$ over the tamarisk stands in this area is due almost completely to the groundwater discharge (Yuan et al., 2014). Hence, the temporal and, in particular, seasonal processes between $E T_{\mathrm{s}}$ and $E T_{\mathrm{g}}$ would be relatively consistent. In addition, an artificial water conveyance project that draws water from the Daxihaizi Reservoir to the lower river channel every year (Tao et al., 2008) has been implemented to improve the lower riparian ecological systems of the Tarim River (Chen et al., 2008). These anthropogenic disturbances, in association with plant growth and weather changes, have altered the normal groundwater regimes and produced variable groundwater level fluctuations in the riparian forest zone. These changes provide ideal field conditions for evaluating the White method for estimating $E T_{\mathrm{g}}$ under variable water level fluctuations by comparing the calculated $E T_{\mathrm{g}}$ with the measured $E T_{\mathrm{s}}$.

We conducted a 2-year field experiment in a typical tamarisk stand in the lower reach of the Tarim River from 2012 to 2013. At this site, precipitation is scarce, and the groundwater level fluctuates at a depth of around $6 \mathrm{~m}$. The $E T_{\mathrm{s}}$ was measured by the eddy covariance (EC) method, and the groundwater table was automatically measured concurrently every half hour. Because of the combined impacts of weather change, plant growth, and variable surface water levels in the Tarim River channel, the dayto-day groundwater level fluctuations were variable during the entire growing seasons. In this study, we focused on the White method expressed by equation (1) and did not consider other modified methods for estimating $E T_{\mathrm{g}}$ based on the diurnal groundwater fluctuations. We evaluated the performance of the White 
method for estimating $E T_{\mathrm{g}}$ under variable water level fluctuations in a riparian tamarisk stand with deep groundwater depth. The influences of the variable water level fluctuations on the $S_{\mathrm{y}}$ and $r$ temporal processes were explored. Some suggestions to improve the White method for desert riparian forests are presented.

\section{MATERIALS AND METHODS}

\section{Site descriptions}

The field experiment was conducted throughout a wellgrowing riparian tamarisk stand in the lower reach of the Tarim River, which is located in the arid northwestern region of China. One of the distinctive features of the study area is the hyper-arid climate. According to the meteorological records of the Tieganlik Weather Station, which is located in the lower Tarim River basin, the mean annual precipitation was $33.7 \mathrm{~mm}$ from 1957 to 2012 . The observed maximal annual precipitation was $75.7 \mathrm{~mm}$ in 1974, and the minimal annual precipitation was $3.4 \mathrm{~mm}$ in 2001. However, the annual potential evapotranspiration can reach more than $2000 \mathrm{~mm}$ (Chen et al., 2006). Precipitation generally occurs in June, July, and August and is scarcely observed in the remaining months. The lower reach of the Tarim River is located between the Taklamagan Desert and the Kuluk Desert, from the Daxihaizi Reservoir to the terminal Taitmar Lake. Water resources in the lower reach of the Tarim River are under strict artificial controls, and water in the Daxihaizi Reservoir is drawn off, contributing to flows in the lower river channel every year (Tao et al., 2008). As a result of this artificial water management in the lower reach of the Tarim River, most plants can gain water from groundwater supplied by lateral seepage of the river rather than rare flooding events (Ye et al., 2009).

The well-growing tamarisk stand selected for observation covers a uniform area of approximately $200 \times 300 \mathrm{~m}$. This area is flat and located at $87^{\circ} 54^{\prime} \mathrm{E}, 40^{\circ} 27^{\prime} \mathrm{N}$, with an altitude of $846 \mathrm{~m}$. The tamarisk stand is one of the bestgrowing tamarisk stands in the lower reach of the Tarim River, with an average height of approximately $2 \mathrm{~m}$. It is also the dominant species in the stand. Under the shrubs, a small amount of herbs (mainly are Alhagi sparsifolia and Glycyrrhiza inflata) grow. Our survey of the vegetation in the vibrant growing season in July 2013 showed that the Simpson diversity index of the observation site was 0.71 ; the maximal vegetation cover was 0.65 , and the leaf area index measured by LAI-2250 (Li-cor, NE, USA) was 1.15.

\section{Field measurements and data processing}

Surface evapotranspiration. An EC system was placed $1.8 \mathrm{~m}$ above the vegetation canopy in the tamarisk stand to measure the stand evapotranspiration. The core flux instrumentation consisted of a high-frequency $(10 \mathrm{~Hz}$ sampling with a 30-min integration period) sonic anemometer (CSAT3), and an open-path infrared $\mathrm{H}_{2} \mathrm{O}$ / $\mathrm{CO}_{2}$ gas analyser (EC150, Campbell Scientific, USA) to measure momentum, heat, vapour, and $\mathrm{CO}_{2}$ flux. A thermocouple (HMP155A-L, VAISALA Co, Finland) was installed $1.5 \mathrm{~m}$ above the canopy to measure air temperature and humidity. For the energy balance test, a CNR4 net radiometer (Kipp and Zonen, The Netherlands) was placed $1.5 \mathrm{~m}$ above the canopy and projected $3 \mathrm{~m}$ horizontally from the tower to measure the net radiation $\left(R_{\mathrm{n}}\right)$. Two heat flux plates (HFP01-L, Campbell Scientific, USA) were buried $0.08 \mathrm{~m}$ below the surface to measure the ground heat flux. Four thermocouple temperature sensors (109, Campbell Scientific, USA) were buried in different locations in the upper 0.02 and $0.06 \mathrm{~m}$ of soil among and beneath the bushes to measure soil temperature. The soil thermal storage was calculated using the integration method of soil temperature gradient analysis (Mayocchi and Bristow, 1995). An automatic rain gauge (52203, RM Young Inc., USA) was placed at an empty plot south of the flux tower to record precipitation. A data-logger (CR3000-NB, Campbell Scientific, USA) was used for raw data collection and online flux data preliminary processing. The meteorological and radiation elements were measured every $30 \mathrm{~min}$.

The post-processing of the EC data involved spectral correction and a two-angle coordinate rotation of the wind-velocity components to reorient the $x$-axis parallel to the local main wind direction. The density correction was also applied to the flux calculations. The half-hourly turbulent fluxes and meteorological variables were again screened to remove abnormal data points caused by sensor malfunction, rain events, and sensor maintenance.

The energy balance was analysed for the EC data. The net radiation $\left(R_{\mathrm{n}}\right)$, latent heat $(L E)$, and sensible heat $(H)$ were obtained from the EC data, and the ground heat flux $(G)$ was calculated from the average of the two soil heat flux plate measurements and the storage of energy in the $8 \mathrm{~cm}$ of soil above the heat flux plates. The canopy storage heat and photosynthetic energy consumption were ignored because of the sparse, low canopy. The slope of the relationship between the half hourly data of net radiation minus ground heat flux $\left(R_{\mathrm{n}}-G\right)$, and the half hourly data for total turbulent flux $(H+L E)$ indicated that the EC underestimates turbulent fluxes by $16 \%$ for both the whole measurement period (slope $=0.84, R^{2}=0.93$ ) and the daytime of the growing seasons (slope $=0.84$, $R^{2}=0.90$ ). The energy balance was forced to close according to the Bowen ratio (Wohlfahrt et al., 2009). Small gaps (i.e. $<2 \mathrm{~h}$ ) in the data were filled by linear interpolation. 
The hourly $E T_{\mathrm{s}}\left(\mathrm{mm} \mathrm{h}^{-1}\right)$ of the riparian tamarisk stands was calculated based on the observed hourly $L E$ value. The daily $E T_{\mathrm{s}}\left(\mathrm{mm} \mathrm{d}^{-1}\right)$ was the sum of the hourly $E T_{\mathrm{s}}$ for 1 day; when the calculated hourly $E T_{\mathrm{s}}$ was negative, it was set to zero.

Groundwater level. Only one groundwater level observational well was installed near the flux tower but monitored over 2 years for the repetitions. The distance of the observational well to the Tarim River channel was $320 \mathrm{~m}$. An automated pressure groundwater level logger (CTD-Diver, Eijkelcamp, The Netherlands) was used to record the groundwater level below the surface at 30-min intervals. The groundwater table was corrected by air pressure measured by the EC system (Gribovszki et al., 2013). A five point moving average was used to smoothen the groundwater data to prevent noise of various origins from impacting the pressure measurements (Loheide et al., 2005). The data were also frequently calibrated in the field with manual measurements of depth to groundwater.

\section{Methodology for the evaluation of White method}

Assumptions. At our observation site, surface evapotranspiration could result from four water sources: (1) groundwater, (2) overflowing flood, (3) precipitation, and (4) antecedent soil water in the root layer. Therefore, the total riparian stand daily $E T_{\mathrm{s}}$ could be defined as follows:

$$
E T_{\mathrm{s}}=E T_{\mathrm{g}}+E T_{\mathrm{f}}+E T_{\mathrm{p}}+E T_{\mathrm{r}}
$$

where $E T_{\mathrm{g}}, E T_{\mathrm{f}}, E T_{\mathrm{p}}$, and $E T_{\mathrm{r}}$ are the daily evapotranspiration from groundwater, flood water, precipitation, and the existing soil water in the root layer, respectively.

Because no flood occurred at our study site during the observation period, $E T_{\mathrm{f}}$ could be neglected. Because of the scarce precipitation, $E T_{\mathrm{p}}$ could also be neglected most of the time. In addition, according to our observation results, the soil water contents in the shallow layers in the study site did not exhibit any obvious temporal change (Yuan et al., 2014), which indicated that the soil water was stable even though it might participate in the root water uptake and ET processes. Thus, $E T_{\mathrm{r}}$ could also be neglected, and $E T_{\mathrm{g}}$ was approximately equal to $E T_{\mathrm{s}}$ at our observation site. Tamarisk is a typical phreatophyte species. Its fine roots largely develop near the water source (Gary, 1963; Qong et al., 2002; Xu et al., 2011). In hyperarid regions, groundwater is commonly the singular water source (Yuan et al., 2015). Therefore, the temporal processes of $E T_{\mathrm{g}}$ were also approximately consistent with those of $E T_{\mathrm{s}}$, particularly for a longer period, such as a season.

Here, we assumed the water movement from groundwater to surface evapotranspiration in the groundwatersoil-plant-atmosphere system in the observed tamarisk stand is in a steady state under the hyper-arid climate. Based on this assumption, we can evaluate the performance of the White method by comparing the $E T_{\mathrm{s}}$ course and $E T_{\mathrm{g}}$ course by measuring the daily and seasonal surface evapotranspiration courses.

Determination of specific yield. $S_{\mathrm{y}}$ is defined as the water volume released from storage per unit drop in the water table height per unit land area (Hillel, 2004). A simulation analysis demonstrated that the $S_{\mathrm{y}}$ estimation was only weakly dependent on the magnitude of the diurnal fluctuations (Loheide et al., 2005). In this study, a readily available $S_{\mathrm{y}}$ (Loheide et al., 2005) was selected. The $S_{\mathrm{y}}$ value was determined solely from the soil texture at the depth of the groundwater table. When the soil texture in the layer of the water level fluctuation magnitude does not change, $S_{\mathrm{y}}$ is constant, but if the soil texture changes, $S_{\mathrm{y}}$ changes.

Based on the observed fluctuation depths of the groundwater level in the 2012 and 2013 growing seasons (see detail in the section on Groundwater hydrographs), we took soil samples at a depth of 5.5-5.8 $\mathrm{m}$ and a depth of 6.0-6.3 m, respectively. The soil textures were obtained using the hydrometer method (Birkeland, 1984). The $S_{\mathrm{y}}$ value was finely determined based on the soil textures using the method presented by Loheide et al. (2005) (Table I). Because the soil textures differed in the layer of the water level that fluctuated in magnitude between the 2012 growing season and the 2013 growing season, the $S_{\mathrm{y}}$ values were also different between the 2 years (Table I).

Calculations of groundwater recharge rate and storage. In the classical White method, the daily mean $r$ is calculated from the slope of the best fit line, which is

Table I. The soil textures at two different depths corresponding to the groundwater fluctuation depths during the two growing seasons of 2012 and 2013 and the readily available specific yield $\left(S_{\mathrm{y}}\right)$ values during the two growing seasons

\begin{tabular}{lccccc}
\hline Sampling depth (m) & Clay (\%) & Silt $(\%)$ & Sandy $(\%)$ & $S_{\mathrm{y}}{ }^{\mathrm{a}}\left(\mathrm{m}^{3} \mathrm{~m}^{-3}\right)$ & Year of $S_{\mathrm{y}}$ applied \\
\hline $5.5-5.8$ & 5.60 & 75.50 & 18.90 & 0.038 & 2013 \\
$6.0-6.3$ & 5.54 & 65.78 & 28.68 & 0.065 & 2012 \\
\hline
\end{tabular}

\footnotetext{
${ }^{\mathrm{a}} S_{\mathrm{y}}$ was determined using the method presented by Loheide et al. (2005).

[Correction added on 11 September 2015, after first online publication on 29 July 2015: The initial header of Table I, third column was 'Sand (\%)' and in the fourth column was 'Silt (\%)'. These has been replaced with 'Silt (\%)' and 'Sandy (\%)' respectively].
} 
obtained from the least square method, to the hydrograph between midnight and $0400 \mathrm{~h}$. It is assumed that this time span is the time period when groundwater evapotranspiration has ceased, and the daily recharge rate is equal to the average groundwater recharge rate over the entire day. Some methods have employed different time spans to fit the slope (Table II). For instance, Miller et al. (2010) derived $r$ by employing the period from $2200 \mathrm{~h}$ at night to $0700 \mathrm{~h}$ the next morning. Obviously, the slope values ( $r$ values) fitted from different time spans are different (Figure 1). When $S_{\mathrm{y}}$ is constant, the change in the $r$ values determines the temporal processes of the calculated $E T_{\mathrm{g}}$. Thus, the calculation method for $r$ is particularly important for the estimation of $E T_{\mathrm{g}}$ temporal processes. In this paper, we employed four time spans to estimate the recharge rate (Table II). The four time spans were: (1) $0000 \mathrm{~h}$ to $0400 \mathrm{~h}$, which is the recommended period in the classical White method, (2) $0000 \mathrm{~h}$ to $0600 \mathrm{~h}$, which is the lengthened time period employed by Loheide (2008), (3) $1800 \mathrm{~h}$ to $0600 \mathrm{~h}$, which is a representative period of rising water levels during the night employed by Rushton (1996), and (4) $2200 \mathrm{~h}$ to $0700 \mathrm{~h}$, another period of rising water levels during the night employed by Miller et al. (2010). All times in this paper refer to local time. Table II lists the $r$ estimation approaches using different time spans that were included in our investigation and their abbreviations, which were named following the researchers' name.

Moreover, we investigated the impacts of averaging the $r$ values over several days, including $2,3,5$, and 7 days. Two-day averaging refers to averaging the calculated recharge rates of the previous night and the subsequent night; 3-day averaging refers to averaging the calculated

Table II. Four recharge rate estimation approaches using different time spans and their abbreviation and annotation in this paper

\begin{tabular}{|c|c|c|}
\hline Time span & Abbreviation & Annotation \\
\hline $0000 \mathrm{~h}-0400 \mathrm{~h}$ & $r_{-}$White & $\begin{array}{l}\text { The recommended } \\
\text { period in the classical } \\
\text { White method }\end{array}$ \\
\hline $0000 \mathrm{~h}-0600 \mathrm{~h}$ & $r_{-}$Loheide & $\begin{array}{l}\text { Lengthened time period } \\
\text { employed by Loheide } \\
\text { (2008) }\end{array}$ \\
\hline $1800 \mathrm{~h} *-0600 \mathrm{~h}$ & $r \_$Rushton & $\begin{array}{l}\text { Water level ascending } \\
\text { time period during the } \\
\text { night employed by } \\
\text { Rushton (1996) }\end{array}$ \\
\hline $2200 \mathrm{~h} *-0700 \mathrm{~h}$ & $r \_$Miller & $\begin{array}{l}\text { Another chosen water } \\
\text { level ascending time } \\
\text { period during the night } \\
\text { employed by Miller } \\
\text { et al. }(2010)\end{array}$ \\
\hline
\end{tabular}

*Times marked with an asterisk refer to the previous day.

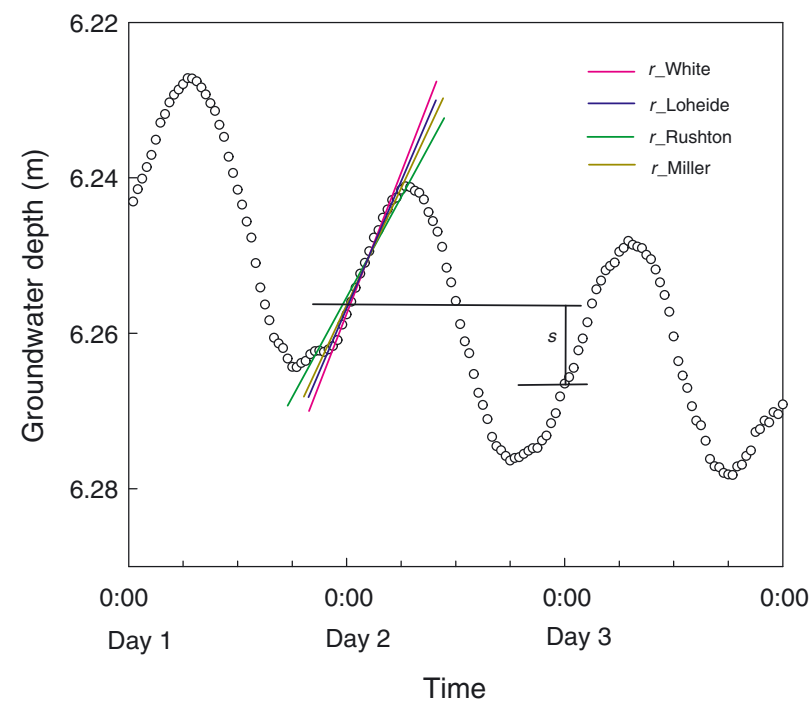

Figure 1. Illustration of the estimation methods for daily recharge rate $(r)$ and storage change $(s)$ of groundwater using the White method based on groundwater level diurnal fluctuation. Four different $r$ estimation approaches based on different time spans are illustrated by the coloured lines

rates of the previous night, that night, and the subsequent night; 5-day averaging refers to averaging the calculated rates of the previous two nights, that night, and the subsequent two nights; 7-day averaging refers to averaging the calculated rates of the previous three nights, that night, and the subsequent two nights.

The value $s$ is the net fall or rise of the water table in the 24-h period. In this paper, $s$ was determined from the difference between the two water levels at $0000 \mathrm{~h}$. today and the subsequent day (Figure 1).

Statistical analysis. The performance of the White method was evaluated by comparing the $E T_{\mathrm{g}}$ with the observed $E T_{\mathrm{s}}$ measured by the EC system using the root mean square error (RMSE) and Nash-Sutcliffe efficiency (NSE). The RMSE was calculated as equation (3):

$$
\mathrm{RMSE}=\sqrt{\frac{\sum_{i=1}^{n}\left(E T_{\mathrm{s}, i}-E T_{\mathrm{g}, i}\right)^{2}}{n}}
$$

The NSE was calculated as equation (4):

$$
\mathrm{NSE}=1-\frac{\sum_{i=1}^{n}\left(E T_{\mathrm{g}, i}-E T_{\mathrm{s}, i}\right)^{2}}{\sum_{i=1}^{n}\left(E T_{\mathrm{s}, i}-\overline{E T_{\mathrm{s}}}\right)^{2}}
$$

where $E T_{\mathrm{s}}$ is the daily surface evapotranspiration observed by the EC method, $E T_{\mathrm{g}}$ is the daily groundwater evapotranspiration estimated by the White method or its modified versions, and $\overline{E T}$ is the mean daily $E T_{\mathrm{s}}$ value over the interval of interest. 
The RMSE value indicates the degree of dispersion of the estimated $E T_{\mathrm{g}}$ relative to the observed $E T_{\mathrm{s}}$ (Willmott et al., 1985). A higher RMSE value indicates a greater variation in the magnitude of the estimated $E T_{\mathrm{g}}$. The NSE value indicates how well the observed $E T_{\mathrm{s}}$ values and estimated $E T_{\mathrm{g}}$ values fit the $1: 1$ line, and the values range from $-\infty$ to 1 , with higher values indicating better agreement (Legates and McCabe, 1999).

Because precipitation will invalidate the assumption discussed in the section on Assumptions, the data from the corresponding time period of precipitation were removed in the statistical analysis.

\section{RESULTS}

\section{Groundwater hydrographs}

The groundwater depth varied between 4.95 and $6.46 \mathrm{~m}$ during the observation period from 1 January 2012 to 9 November 2013, and a general upward trend of the groundwater level was observed during the 2-year period (Figure 2). The oblique line area in Figure 2 corresponds to the growing seasons. In the non-growing seasons, the groundwater level usually moved upward slowly over time and relatively stable, but in the growing seasons, the groundwater level exhibited V-shaped seasonal variations. The groundwater level often began to decline continuously after the onset of the growing season (Figure 2), suggesting groundwater consumption due to plant water uptake. Around mid-August, the groundwater level suddenly rose, which indicated that the plant water uptake was less than the lateral seepage. The groundwater level rising was not due to a decrease in plant water consumption (Yuan et al., 2014) but was the result of an in lateral seepage resulting from the artificial water conveyance from the Daxihaizi reservoir to the lower reach of the Tarim River at this time every year (Ye et al., 2009). The V-shaped seasonal variations of the ground- water level indicated that both plant water uptake and the artificial water conveyance controlled the seasonal variation of the groundwater level at our study site, which led to variable water level fluctuations. The variability of the water level fluctuations was mainly apparent in the following aspects.

First, because of the artificial water conveyance to the river channel of the lower reach of the Tarim River in August every year, the groundwater level in our observation site exhibited a downward trend in the first half and an upward trend in the second half of a growing season. The V-shaped seasonal variations formed two opposite long-term fluctuation trends of groundwater level, corresponding to the discharge process and recharge processes of groundwater, respectively.

Second, because of the differences in plant water consumption in different phenological stages, the groundwater evapotranspiration rates usually exhibited differences at different phenological stages of the plant, resulting in differing magnitudes of diurnal fluctuations of the groundwater level in different growing seasons. The diurnal fluctuation was particularly obvious in the vibrant growing seasons (Figures $3 b$ and c) but weak in the early and late portions of the growing season (Figures 3a and d). Weak diurnal fluctuations can cause larger uncertainty in the recharge rate determination, as illustrated in Figures $3 \mathrm{a}$ and d. Groundwater level fluctuations were usually highly irregular during the low ET season, with low recharge rates (Figure 3d) and even negative correlation with time (Figure 3a).

Third, daily variations of weather can influence the surface evapotranspiration and, consequently, the groundwater evapotranspiration. For example, a cloudy day or precipitation can reduce groundwater consumption, and thus, a general downward groundwater level trend becomes a transient upward level trend (inset in Figure 2). These fluctuations were particularly obvious in June and July of 2013. This transient opposing fluctuation trend

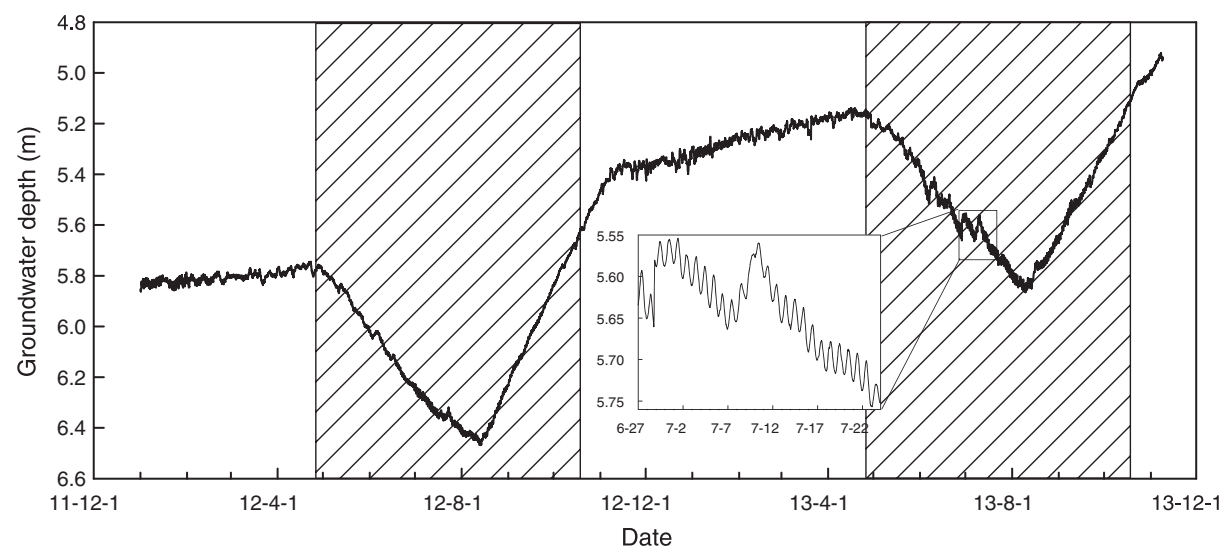

Figure 2. Groundwater table hydrograph during the observation period from 1 January 2012, to 9 November 2013. The oblique line areas correspond to the growing seasons of the observed tamarisk stand 

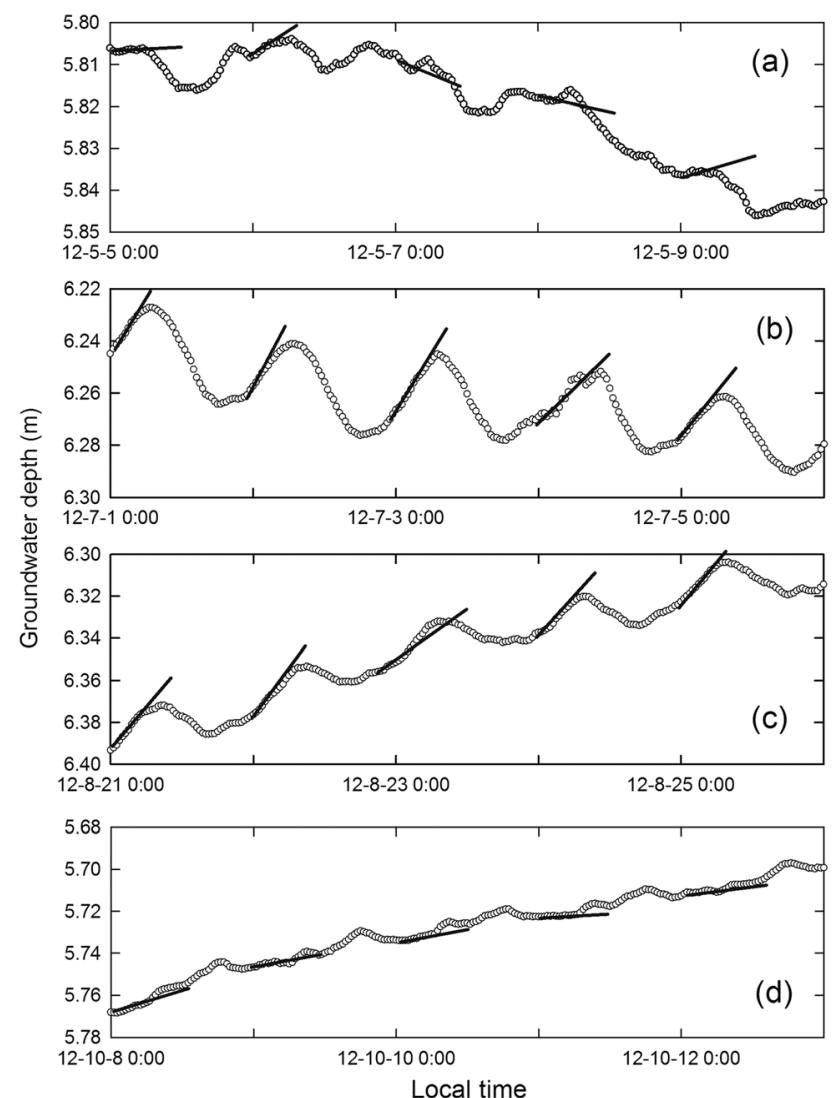

Figure 3. Four examples of diurnal fluctuations in different stages of a growing season. The solid lines illustrate the daily recharge rate estimation approaches. (a) An example in the early stage of the growing season; (b) an example in the first half of the vibrant growing season; (c) an example in the second half of the vibrant growing season; and (d) an example in the late stage of the growing season

increased the complexity of the groundwater level fluctuations in our experiments.

Fourth, the depths of the groundwater level fluctuations differed between the 2012 and 2013 growing seasons. The groundwater depth fluctuated from 5.63 to $6.46 \mathrm{~m}$ in the 2012 growing season and from 5.09 to $5.86 \mathrm{~m}$ in the 2013 growing season, resulting in different $S_{\mathrm{y}}$ values between the 2 years due to the different soil textures at different depths.

These complex groundwater level fluctuations in our experiments provided ideal conditions to evaluate the performance of the White method under variable groundwater level fluctuations in field environments with deep groundwater levels.

\section{Seasonal variations of $E T_{\mathrm{g}}$ and $E T_{\mathrm{s}}$}

The groundwater evapotranspiration was very weak in non-growing seasons. Thus, the estimation of $E T_{\mathrm{g}}$ in the non-growing seasons using the White method would be not meaningful in our study area. Here, we selected only the growing seasons of the observed tamarisk stand to explore the performance of the White method. In the calculations of $E T_{\mathrm{g}}$ in this section, we chose the $r$ LLoheide approach to estimate the $r$ value because the $r$ LLoheide method was validated to be the best $r$ estimation method among the four employed $r$ estimation approaches, as will be discussed in the next section.

Comparisons of the temporal courses of the daily $E T_{\mathrm{g}}$ and the daily $E T_{\mathrm{s}}$ in 2012 and 2013 revealed that the seasonal variations in the estimated $E T_{\mathrm{g}}$ and the observed $E T_{\mathrm{s}}$ coincided $\left(R^{2}=0.67\right)$, which not only confirmed that our assumptions on the relationship between $E T_{\mathrm{g}}$ and $E T_{\mathrm{s}}$ in the study area were reasonable but also indicated that the White method could adequately capture the seasonal variations of $E T_{\mathrm{g}}$. However, we also observed that the range of the day-to-day fluctuations in $E T_{\mathrm{g}}$ was usually larger than that of $E T_{\mathrm{s}}$ (Figure 4).

In the calculations of the White method, because $S_{\mathrm{y}}$ was set to a constant value for an entire growing season (Table I), the estimation of the seasonal variation of $E T_{\mathrm{g}}$ was determined by the estimation of the variables $r$ and $s$. Figure 4 also shows the seasonal variations of $r$ and $s$ in 2012 and 2013. The variations of the $s$ value were determined by the difference in the day-to-day fluctuations in groundwater level. In the first half of the growing season, during which a downward trend of groundwater level occurred (Figure 2), most $s$ values were positive (Figure 4), and in the second half of the growing season, most $s$ values were negative (Figure 4) because of the upward trend of groundwater level (Figure 2). The seasonal courses of $s$ did not coincide with those of $E T_{\mathrm{g}}\left(R^{2}=0.16\right)$, indicating that the fluctuating seasonal trend of groundwater level did not substantially influence the estimations of the seasonal variations of $E T_{\mathrm{g}}$ based on the White method. By contrast, the seasonal courses of $r$ approximately coincided with those of $E T_{\mathrm{g}}\left(R^{2}=0.68\right)$ (Figure 4), revealing the critical role of the $r$ value in the estimations of the seasonal variations of $E T_{\mathrm{g}}$. Sensitivity analysis of equation (1) also revealed that the impact of the $r$ values on the $E T_{\mathrm{g}}$ values was more significant than that of the $s$ values. As variables $r$ and $s$ increase from $10 \%$ to $20 \%$, the estimated $E T_{\mathrm{g}}$ values increase from approximately $1.3 \%$ to $2.5 \%$ for $s$ and from approximately $11.3 \%$ to $22.5 \%$ for $r$, indicating that a slight error in $r$ could cause a larger deviation in $E T_{\mathrm{g}}$ estimates.

Although the seasonal variations in the estimated $E T_{\mathrm{g}}$ and observed $E T_{\mathrm{s}}$ coincided, some obvious differences between $E T_{\mathrm{s}}$ and $E T_{\mathrm{g}}$ occurred during an entire growing season. Generally, these differences mainly occurred under two conditions. One condition was the time period of the early or late portion of the growing season, when the daily fluctuation range of groundwater levels was still small. The estimated $E T_{\mathrm{g}}$ often deviated from the observed $E T_{\mathrm{s}}$ in these periods. A negative or abnormal 

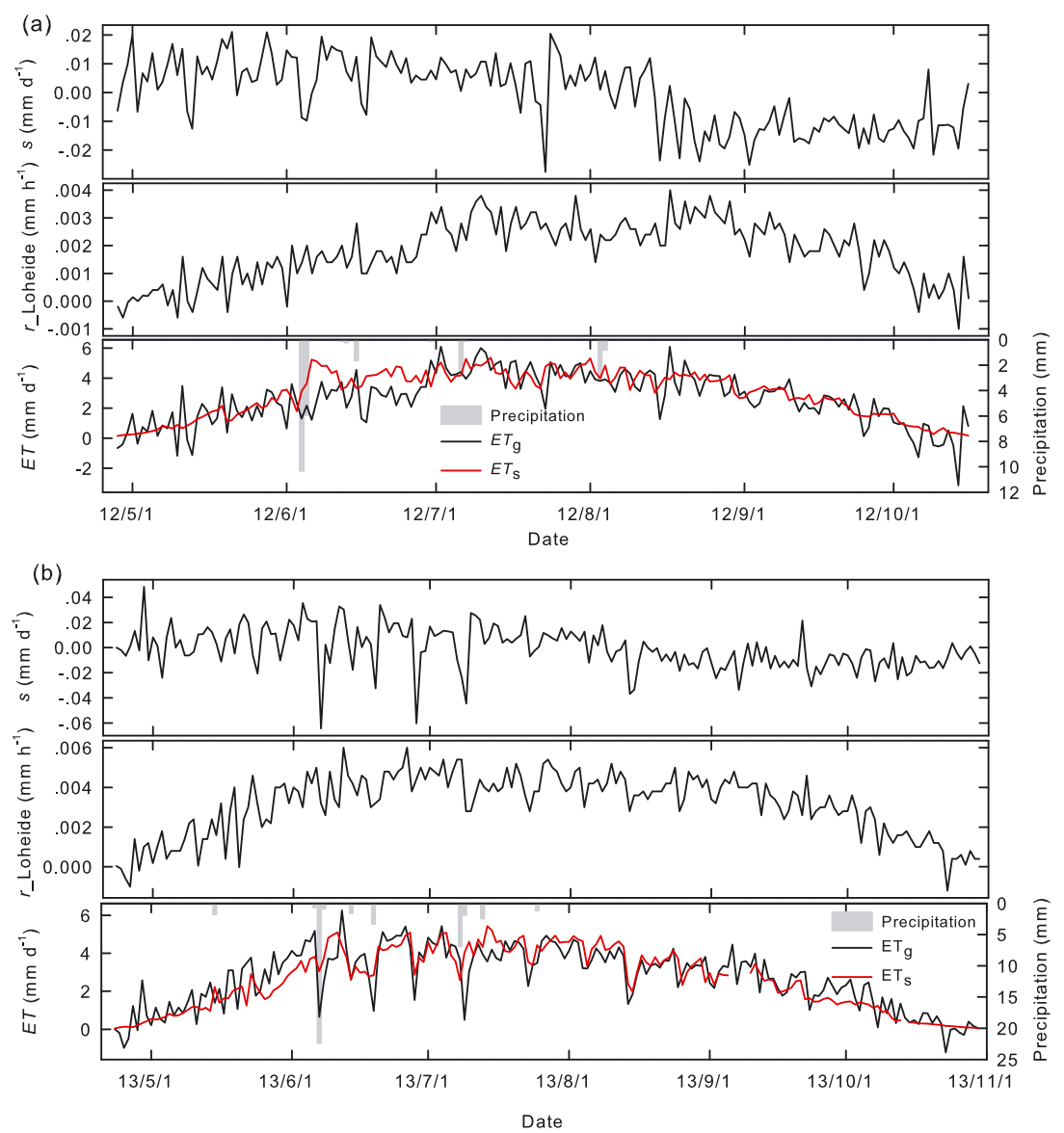

Figure 4. Seasonal variations of the estimated groundwater evapotranspiration $\left(E T_{\mathrm{g}}\right)$, the observed surface evapotranspiration $\left(E T_{\mathrm{s}}\right)$, corresponding daily recharge rate $(r)$ and storage change $(s)$ of groundwater, and precipitations in (a) the 2012 growing season and (b) the 2013 growing season.

value of $E T_{\mathrm{g}}$ was occasionally obtained during these periods (Figure 4). Comparison with the corresponding values of $r$ and $s$ (Figure 4) revealed that the weak and irregular diurnal fluctuation of groundwater level in these periods (Figures 3a and d) caused these abnormal values of $r$ and $s$. Another condition was precipitation events. After obvious precipitation events, the estimated $E T_{\mathrm{g}}$ was usually significantly less than the observed $E T_{\text {s }}$ (Figure 4). In our observation area with a deep groundwater depth and a hyper-arid climate, precipitation increases the soil moisture in the surface layer, which subsequently increases surface evapotranspiration because of the increasing soil evaporation, while the transpiration of a phreatophytic plant such as tamarisk and the associated groundwater consumption would not increase. As a result, $E T_{\mathrm{g}}$ would be less than $E T_{\mathrm{s}}$ after a precipitation event. This phenomenon was particularly obvious after large precipitation events during the 2 years of growing seasons (Figure 4). Therefore, the differences between $E T_{\mathrm{g}}$ and $E T_{\mathrm{s}}$ after obvious precipitation events further support the validity of the $E T_{\mathrm{g}}$ estimation using the White method.

\section{Comparisons of $E T_{g}$ based on different $r$ estimation} approaches

The fitted $r$ values differed based on different time spans. The estimated $E T_{\mathrm{g}}$ values using $r$ estimation from four time spans, which were (1) $0000 \mathrm{~h}$ to $0400 \mathrm{~h}$, (2) $0000 \mathrm{~h}$ to $0600 \mathrm{~h},(3) 1800 \mathrm{~h}$ to $0600 \mathrm{~h}$, and (4) $2200 \mathrm{~h}$ to $0700 \mathrm{~h}$ (Table II), exhibited obvious differences. Statistically comparing $E T_{\mathrm{g}}$ with $E T_{\mathrm{s}}$ allowed the performance of the four different time spans of $r$ estimation to be examined (Figure 5). Here, a lower RMSE and a higher NSE indicate best fit between $E T_{\mathrm{g}}$ and $E T_{\mathrm{s}}$.

In general, the performances of the $E T_{\mathrm{g}}$ estimations in 2013 (Figure 5b) were better than those in 2012 (Figure 5a), and the performances of the four approaches of $r$ estimations exhibited similar differences in the 2 years of growing seasons. In 2012, the highest NSE (0.57) was achieved when employing the $r_{-}$Loheide approach. In 2013, the highest NSE (0.73) was achieved when employing the $r_{-}$Miller approach, while the NSE value obtained by employing the $r_{-}$Loheide approach was 0.72 , indicating that the $r_{-}$Loheide approach performed as well 

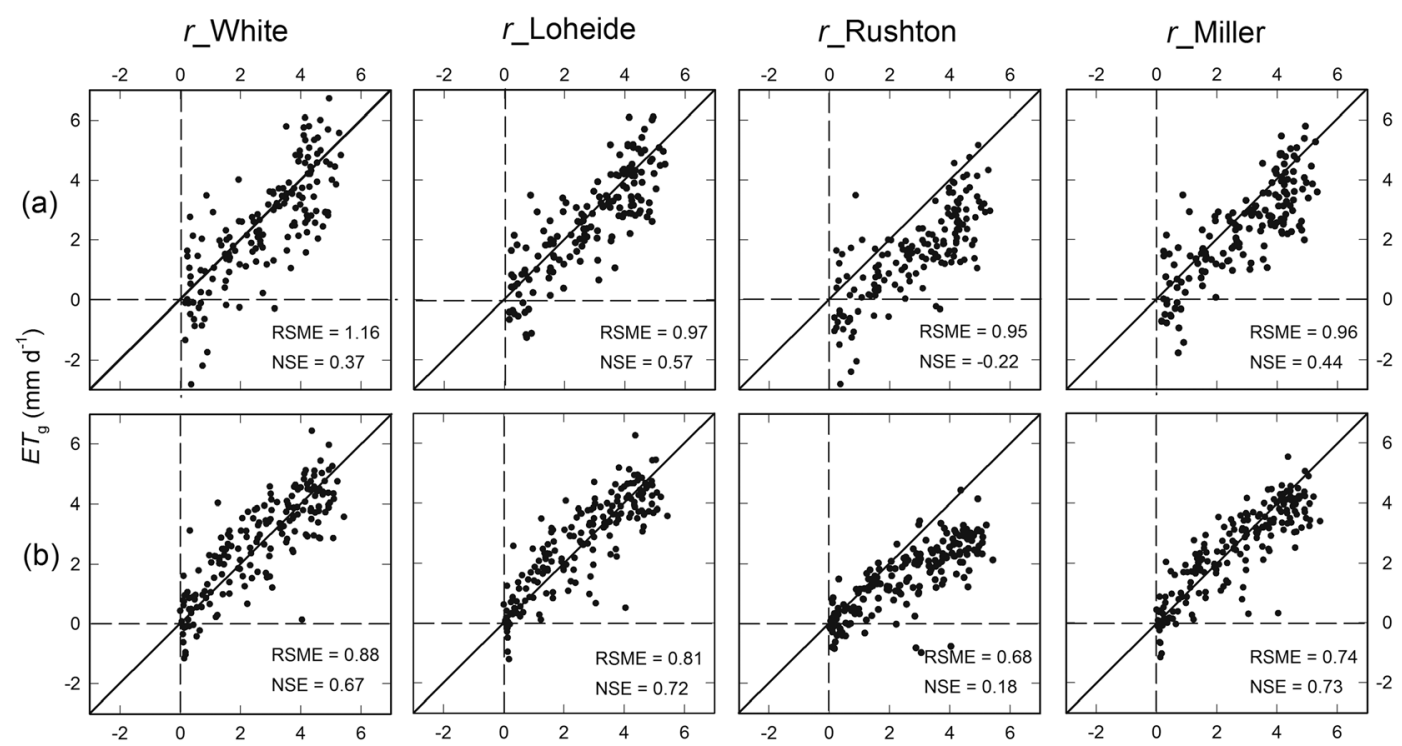

$E T_{\mathrm{s}}\left(\mathrm{mm} \mathrm{d}^{-1}\right)$

Figure 5. Comparisons of the observed surface evapotranspiration $\left(E T_{\mathrm{s}}\right)$ and the estimated groundwater evapotranspiration $\left(E T_{\mathrm{g}}\right)$ based on four different recharge rate estimation approaches in (a) the 2012 growing season and (b) the 2013 growing season. A one-to-one line is shown in each plot. Root mean square errors (RMSE) are in millimetre per day, Nash-Sutcliffe efficiencies (NSE) are dimensionless

as the $r$ _Miller approach in 2013. The lowest NSE values in both years were obtained when employing the $r_{-}$Rushton approach. The estimated $E T_{\mathrm{g}}$ values were substantially less than the observed $E T_{\mathrm{s}}$ values based on the $r_{-}$Rushton approach, which was due to the lower $r$ values obtained using the $r_{-}$Rushton approach. The classical White method employing the time span of midnight to $0400 \mathrm{~h}$ performed worse than the $r_{-}$Loheide and $r_{-}$Miller approaches, but the estimated $E T_{\mathrm{g}}$ values based on the $r_{-}$White approach generally did not substantially deviate from the observed $E T_{\text {s }}$ values, in contrast to the $r_{-}$Rushton approach.

With respect to the RMSE values, the order from low to high was $r_{-}$Rushton, $r_{-}$Miller, $r_{-}$Loheide, and $r_{-}$White (Figure 5), indicating that the use of longer time span to fit the $r$ value reduced the magnitude of the day-to-day fluctuations of the estimated $E T_{\mathrm{g}}$. Thus, the use of a shorter time span to fit the $r$ value produced larger temporal fluctuations of the $r$ estimation, and lengthening the time span decreased the day-to-day fluctuations of the $r$ values. However, for the $r_{-}$Rushton approach, lower overall $r$ values were observed for the longest time period.

In summary, the approach employing the time period of midnight to $0600 \mathrm{~h}$ produced the best estimation of $E T_{\mathrm{g}}$. The approach employing the time period of $1800 \mathrm{~h}$ to $0600 \mathrm{~h}$ substantially underestimated the $E T_{\mathrm{g}}$ value. The classical White method employing the time period of midnight to $0400 \mathrm{~h}$ yielded the largest day-to-day fluctuations of $E T_{\mathrm{g}}$. The performance of the approach employing the time period of $2200 \mathrm{~h}$ to $0700 \mathrm{~h}$ was not consistent between the growing seasons of 2012 and 2013 but was superior to that of the classical White method.

\section{Comparisons of $E T_{g}$ based on different averaged $r$ values}

Figure 6 shows the $E T_{\mathrm{g}}$ seasonal variations based on four different averaged (2 or more days) $r$ values and their comparisons with the $E T_{\mathrm{g}}$ determined from the nonaveraged (1 day) $r$ values and observed $E T_{\mathrm{s}}$. Here, the $r$ values were estimated by the $r_{-}$Loheide approach. None of the $E T_{\mathrm{g}}$ temporal courses based on the different averaged $r$ values exhibited significant differences $\left(R^{2}>0.93\right)$, and the seasonal trends were approximately consistent with that of the observed $E T_{\text {s }}$ (Figure 6). However, as shown in Figure 6, the daily fluctuation of $E T_{\mathrm{g}}$ based on non-averaged $r$ values was obviously larger than that based on averaged $r$ values. The statistical parameters, including the RMSE in Table III, further emphasized these differences. For the four approaches for $r$ estimation, all of the RMSE values based on the non-averaged $r$ values were substantially larger than those based on the averaged $r$ values in both 2012 and 2013 (Table III), indicating that averaging $r$ for that day and neighbouring days could smooth the fluctuation of the $r$ value and consequently lessen the daily fluctuation of the $E T_{\mathrm{g}}$ values. In addition, the NSE values based on the nonaveraged $r$ values were all substantially less than those based on the averaged $r$ values (Table III), further indicating that averaging $r$ for that day and neighbouring days could substantially improve the $E T_{\mathrm{g}}$ estimations.

However, the RMSE values did not substantially decrease and the NSE values did not substantially increase when the days for averaging $r$ increased from 2 to 7 days for all four approaches of $r$ estimation in both 2012 and 2013 (Table III), indicating that 3 to 7 days for 


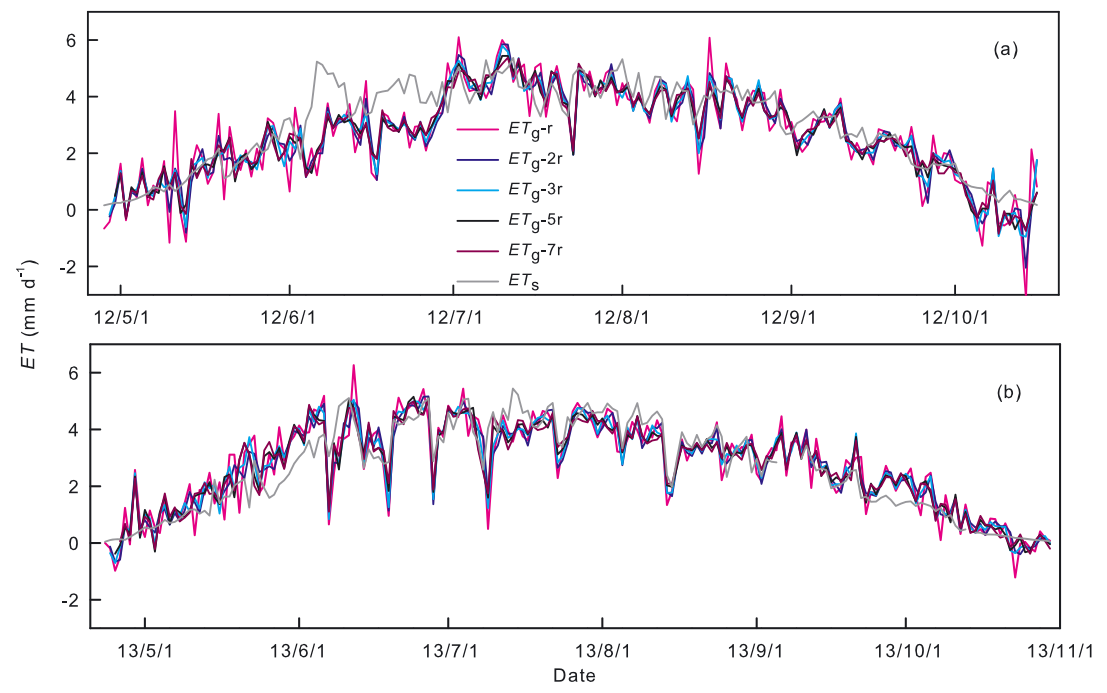

Figure 6. Seasonal variations of estimated groundwater evapotranspiration $\left(E T_{\mathrm{g}}\right)$ based on different averaged recharge rate $(r)$ values and their comparisons with the $E T_{\mathrm{g}}$ obtained from the non-averaged $r$ values and the observed surface evapotranspiration (ET $T_{\mathrm{s}}$ ) during (a) the 2012 growing season and (b) the 2013 growing season. The $r$ refers to non-averaged, $2 r$ refers to 2-day averaging, $3 r$ refers to 3-day averaging, $5 r$ refers to 5-day averaging, and $7 r$ refers to 7 -day averaging.

Table III. Statistical results and performances of groundwater evapotranspiration estimates based on different averaged recharge rate $(r)$ values for the four $r$ estimation approaches during the 2012 and 2013 growing seasons

\begin{tabular}{|c|c|c|c|c|c|c|c|}
\hline \multirow[b]{2}{*}{ Methods } & \multirow[b]{2}{*}{ Year } & \multirow{2}{*}{$\begin{array}{c}\text { Statistical } \\
\text { parameters }^{\mathrm{a}}\end{array}$} & \multicolumn{5}{|c|}{ Averaged $r^{\mathrm{b}}$} \\
\hline & & & $r$ & $2 r$ & $3 r$ & $5 r$ & $7 r$ \\
\hline \multirow[t]{4}{*}{ r_White } & \multirow[t]{2}{*}{2012} & RMSE & 1.16 & 0.89 & 0.83 & 0.74 & 0.72 \\
\hline & & NSE & 0.37 & 0.61 & 0.66 & 0.72 & 0.74 \\
\hline & \multirow{2}{*}{2013} & RMSE & 0.88 & 0.69 & 0.69 & 0.64 & 0.62 \\
\hline & & NSE & 0.67 & 0.79 & 0.79 & 0.81 & 0.82 \\
\hline \multirow[t]{4}{*}{$r \_$Loheide } & \multirow[t]{2}{*}{2012} & RMSE & 0.97 & 0.76 & 0.71 & 0.64 & 0.62 \\
\hline & & NSE & 0.57 & 0.72 & 0.75 & 0.79 & 0.80 \\
\hline & \multirow[t]{2}{*}{2013} & RMSE & 0.81 & 0.62 & 0.65 & 0.62 & 0.60 \\
\hline & & NSE & 0.72 & 0.82 & 0.81 & 0.82 & 0.83 \\
\hline \multirow{4}{*}{$r \_$Rushton } & \multirow{2}{*}{2012} & RMSE & 0.95 & 0.70 & 0.66 & 0.62 & 0.61 \\
\hline & & NSE & -0.22 & -0.05 & -0.02 & 0.00 & -0.01 \\
\hline & \multirow[t]{2}{*}{2013} & RMSE & 0.68 & 0.57 & 0.59 & 0.56 & 0.55 \\
\hline & & NSE & 0.18 & 0.24 & 0.23 & 0.24 & 0.25 \\
\hline \multirow[t]{4}{*}{ r_Miller } & \multirow[t]{2}{*}{2012} & RMSE & 0.96 & 0.75 & 0.69 & 0.62 & 0.62 \\
\hline & & NSE & 0.44 & 0.60 & 0.64 & 0.67 & 0.68 \\
\hline & \multirow{2}{*}{2013} & RMSE & 0.74 & 0.58 & 0.62 & 0.59 & 0.57 \\
\hline & & NSE & 0.73 & 0.81 & 0.79 & 0.80 & 0.81 \\
\hline
\end{tabular}

${ }^{\text {a }}$ Root mean square errors (RMSE) are in millimetre per day, Nash-Sutcliffe efficiencies (NSE) are dimensionless.

${ }^{\mathrm{b}} r$ refers to non-averaged, $2 r$ refers to 2 -day averaging, $3 r$ refers to 3 -day averaging, $5 r$ refers to 5 -day averaging, and $7 r$ refers to 7 -day averaging.

averaging $r$ did not substantially improve the performance of the White method for estimating $E T_{\mathrm{g}}$.

\section{DISCUSSIONS}

\section{Determination of specific yield}

$S_{\mathrm{y}}$ is of crucial importance to estimating $E T_{\mathrm{g}}$ because errors in specific yield estimates directly translate to errors in $E T_{\mathrm{g}}$ estimates (Alley et al., 2002; Lautz, 2008). The $S_{\mathrm{y}}$ value in our study differs by nearly twofold between 2012 and 2013 and provides a more accurate value of $E T_{\mathrm{g}}$ when compared with $E T_{\mathrm{s}}$. If the employed $S_{\mathrm{y}}$ value was set to one of the two values in the 2 years, the estimated $E T_{\mathrm{g}}$ values in another year would be considerably larger or less than the reasonable values. These results indicate that fine, correct soil texture data must be obtained for the layers in which the groundwater level fluctuates for the $S_{\mathrm{y}}$ 
determination and also indicate that the method to determine the $S_{\mathrm{y}}$ value presented by Loheide et al. (2005) from a saturated-unsaturated flow simulation analysis is feasible for the desert riparian forest zone with deep groundwater present in our study area.

$S_{\mathrm{y}}$ usually differs if the water table is in discharge or recharge because of the difference in drainable and fillable porosity (Nachabe, 2002). The groundwater table in our observation site exhibited two opposing long-term change trends throughout the growing season, representing the discharge process and recharge process. However, the $E T_{\mathrm{g}}$ estimations obtained using a constant $S_{\mathrm{y}}$ value did not exhibit abnormal trends between the two processes, indicating that recharge versus discharge characteristics of the groundwater system was inconsequential in this setting. This confirms that for deep groundwater conditions, a constant $S_{\mathrm{y}}$ value for a defined porous medium can often be assumed (Fahle and Dietrich, 2014).

\section{Estimation of the recharge rate}

The classical White method considers that the recharge rate between midnight and $0400 \mathrm{~h}$ is approximately equal to the average recharge rate for the day because the water level is approximately at its mean value of the day, that is, corresponding to the mean gradient between water level and recovery source (Loheide et al., 2005). The lysimeter measurements by Fahle and Dietrich (2014) indicated that the recharge rate during this period was (slightly) lower than the daily mean, hence leading to underestimation when this period is used. However, our results indicated that the recharge rate between midnight and $0400 \mathrm{~h}$ did not lead to an underestimation of $E T_{\mathrm{g}}$ but to the largest daily fluctuations (largest RMSE) of $E T_{\mathrm{g}}$ among all four time spans examined (Figures 4 and 5). These results suggest that the recharge rate between midnight and $0400 \mathrm{~h}$ is higher or lower than the daily mean in some way but is not consistently lower than the daily mean, in contrast to the outcome predicted by Fahle and Dietrich (2014). Because direct measurements of the recharge rate cannot be conducted in field environments, we were unable to judge under what conditions the fitted recharge rate during a time span would be higher or lower than the daily mean. However, the longer time spans for fitting the $r$ values decreased the daily fluctuations of $E T_{\mathrm{g}}$, indicating that usage of longer time spans could decrease the daily fluctuations of $r$ values. This result is consistent with that of Fahle and Dietrich (2014), but we observed that the longest time span, from $1800 \mathrm{~h}$ to $0600 \mathrm{~h}$, which represented the entire groundwater level upward time period for 1 day, led to obviously low $r$ values, particularly when groundwater consumption was high (Figure 4), indicating that the time span from $1800 \mathrm{~h}$ to
$0600 \mathrm{~h}$ was not appropriate for fitting the recharge rate. This result differs greatly from that of Fahle and Dietrich (2014), who observed that the time span from $1800 \mathrm{~h}$ to $0600 \mathrm{~h}$ yielded the best estimation of the recharge rate. Contrasting results with those of Fahle and Dietrich (2014) are likely attributed to differences in groundwater depth and plant species. Our experiment was conducted in a xeric phreatophyte stand with a deep groundwater table, while Fahle and Dietrich's experiment was conducted at a grassland site with shallow groundwater depth. We recommend that the time span for $r$ estimation should be evaluated in each study.

Our results indicated that averaging 2 or more days of $r$ values substantially improved the performance of the White method for estimating $E T_{\mathrm{g}}$. However, a 2-day average of $r$ values is sufficient to improve the $E T_{\mathrm{g}}$ estimation by the White method, consistent with that of Fahle and Dietrich (2014). We concluded that determining $r$ by employing the time span from $0000 \mathrm{~h}$ to $0600 \mathrm{~h}$ to fit the $r$ values and then averaging 2 days of $r$ values was optimal for the specific conditions of our study.

\section{Influences of variable groundwater level fluctuations and anthropogenic disturbance}

In the vibrant growing season from June to August in the observed tamarisk stand, the diurnal fluctuations of the groundwater level were usually regular and distinct. During this period, the estimated $E T_{\mathrm{g}}$ based on groundwater level diurnal fluctuations generally matched $E T_{\mathrm{s}}$. However, in the early and late portions of the growing seasons, many negative or abnormal values of $E T_{\mathrm{g}}$ were obtained because of the weak diurnal fluctuation of the groundwater level. These results indicate some limits of the seasonal processes estimation of $E T_{\mathrm{g}}$ using groundwater level diurnal fluctuations in stands of phreatophytes. In the early and late portions of the growing season, weak diurnal fluctuations of the groundwater level due to low plant transpiration lead to a high uncertainty of $r$ estimation, with high scatter and fluctuation of the $r$ values. Smoothed $r$ values can usually be obtained by averaging the $r$ values over a period of days, thereby improving the $E T_{\mathrm{g}}$ estimations in these periods.

Precipitation events and daily changes in plant water consumption can affect groundwater hydrographs, resulting in complex groundwater level diurnal fluctuations. Water level signals vary at frequencies other than diurnal. Zhu et al. (2011) analysed the impacts of the interferences on the $E T_{\mathrm{g}}$ estimations and noted that the interfered groundwater level diurnal fluctuations caused large errors of the $E T_{\mathrm{g}}$ estimations. In our experiments, the normal groundwater level diurnal fluctuations were occasionally affected by precipitation events or daily changes in plant water consumption. These complex 
groundwater level signals were usually observed in June and July (Figure 2). However, the corresponding $E T_{\mathrm{g}}$ estimated by the White method did not exhibit large errors, most likely because the effects on the groundwater level fluctuation at our experimental site were not as strong as those observed by Zhu et al. (2011). In general, the slight effects on the diurnal groundwater level fluctuation did not influence the $E T_{\mathrm{g}}$ estimations determined by the White method.

In our study area, the dam release from the Daxihaizi Reservoir in August every year altered the groundwater hydrographs. Two opposing long-term change trends of the groundwater level throughout the growing season occurred because of the anthropogenic disturbance. However, the additional inputs to the hydrological system did not have any effect on the $E T_{\mathrm{g}}$ estimation. The artificial water conveyance from the Daxihaizi Reservoir to the lower reach of the Tarim River mainly changed the long-term trend rather than the diurnal fluctuation of groundwater table. Consequently, the $r$ and $s$ estimations based on the groundwater diurnal fluctuation signals would generally not be impacted by this long-term disturbance.

\section{CONCLUSIONS}

The White method based on diurnal fluctuations of groundwater level is feasible to estimate groundwater evapotranspiration in a desert riparian tamarisk stand with deep groundwater depth when the $S_{\mathrm{y}}$ and $r$ values are properly determined or treated. The readily available $S_{\mathrm{y}}$ must be finely determined based on the soil textures in the layers in which the groundwater level fluctuates. Estimating $r$ values by employing the time span from $0000 \mathrm{~h}$ to $0600 \mathrm{~h}$ and averaging 2 days of $r$ values is suggested in xeric riparian settings. Our results provide valuable references for the application of the White method for estimating $E T_{\mathrm{g}}$ in riparian forests with deep groundwater depth.

\section{ACKNOWLEDGEMENTS}

This study was funded by the National Natural Science Foundation of China (no. 41271050). We thank Professor Yi Luo for his valuable suggestions and discussions. We are also grateful to the two anonymous reviewers for their careful comments and suggestions, which contributed to improving the paper.

\section{REFERENCES}

Alley WM, Healy RW, LaBaugh JW, Reilly TE. 2002. Hydrology - flow and storage in groundwater systems. Science 296: 1985-1990. DOI:10.1126/science.1067123.
Birkeland PW. 1984. Soils and Geomorphology. Oxford Univ: Press, New York.

Chen YN, Pang ZH, Chen YP, Li WH, Xu CC, Hao XM, Huang X, Huang TM, Ye ZX. 2008. Response of riparian vegetation to watertable changes in the lower reaches of Tarim River, Xinjiang Uygur, China. Hydrogeology Journal 16: 1371-1379. DOI:10.1007/s10040008-0306-1.

Chen YN, Zilliacus H, Li WH, Zhang HF, Chen YP. 2006. Ground-water level affects plant species diversity along the lower reaches of the Tarim River, Western China. Journal of Arid Environments 66: 231-246. DOI:10.1016/j.jaridenv.2005.11.009.

Cheng D-h, Li Y, Chen X, Wang W-k, Hou G-c, Wang C-1. 2013. Estimation of groundwater evaportranspiration using diurnal water table fluctuations in the Mu Us Desert, northern China. Journal of Hydrology 490: 106-113. DOI:10.1016/j.jhydrol.2013.03.027.

Dolan TJ, Hermann AJ, Bayley SE, Zoltek J. 1984. Evapotranspiration of a Florida, USA, fresh-water wetland. Journal of Hydrology 74: 355-371. DOI: 10.1016/0022-1694(84)90024-6.

Fahle M, Dietrich O. 2014. Estimation of evapotranspiration using diurnal groundwater level fluctuations: comparison of different approaches with groundwater lysimeter data. Water Resources Research 50: 273-286. DOI:10.1002/2013WR014472.

Gary HL. 1963. Root distribution of five-stamen tamarisk, seepwillow, and arrowweed. Forest Science 9: 311-314.

Gribovszki Z, Kalicz P, Szilágyi J. 2013. Does the accuracy of fine-scale water level measurements by vented pressure transducers permit for diurnal evapotranspiration estimation? Journal of Hydrology 488: 166-169. DOI:10.1016/j.jhydrol.2013.03.001.

Gribovszki Z, Kalicz P, Szilagyi J, Kucsara M. 2008. Riparian zone evapotranspiration estimation from diurnal groundwater level fluctuations. Journal of Hydrology 349: 6-17. DOI:10.1016/j.jhydrol.2007.10.049.

Hatler WL, Hart CR. 2009. Water loss and salvage in saltcedar (Tamarix spp.) stands on the Pecos River, Texas. Invasive Plant Science and Management 2: 309-317. DOI:10.1614/Ipsm-09-009.1.

Hillel D. 2004. Introduction to Evironmental Soil Physics. Academic Press.

Lautz LK. 2008. Estimating groundwater evapotranspiration rates using diurnal water-table fluctuations in a semi-arid riparian zone. Hydrogeology Journal 16: 483-497. DOI:10.1007/s10040-007-0239-0.

Legates DR, McCabe GJ. 1999. Evaluating the use of 'goodness-of-fit' measures in hydrologic and hydroclimatic model validation. Water Resources Research 35: 233-241. DOI:10.1029/1998wr900018.

Loheide SP. 2008. A method for estimating subdaily evapotranspiration of shallow groundwater using diurnal water table fluctuations. Ecohydrology 1: 59-66. DOI:10.1002/Eco.7.

Loheide SP, Butler JJ, Gorelick SM. 2005. Estimation of groundwater consumption by phreatophytes using diurnal water table fluctuations: a saturated-unsaturated flow assessment. Water Resources Research 41W07030: . DOI:10.1029/2005wr003942.

Lubczynski MW. 2009. The hydrogeological role of trees in water-limited environments. Hydrogeology Journal 17: 247-259. DOI: 10.1007/ s10040-008-0357-3.

Martinet MC, Vivoni ER, Cleverly JR, Thibault JR, Schuetz JF, Dahm CN. 2009. On groundwater fluctuations, evapotranspiration, and understory removal in riparian corridors. Water Resources Research 45: W05425. DOI: 10.1029/2008wr007152.

Mayocchi CL, Bristow KL. 1995. Soil surface heat-flux - some general questions and comments on measurements. Agricultural and Forest Meteorology 75: 43-50. DOI:10.1016/0168-1923(94)02198-S.

Miller GR, Chen XY, Rubin Y, Ma SY, Baldocchi DD. 2010. Groundwater uptake by woody vegetation in a semiarid oak savanna. Water Resources Research 46: W10503. DOI: 10.1029/2009wr008902.

Mould DJ, Frahm E, Salzmann T, Miegel K, Acreman MC. 2010. Evaluating the use of diurnal groundwater fluctuations for estimating evapotranspiration in wetland environments: case studies in southeast England and northeast Germany. Ecohydrology 3: 294-305.

Nachabe M. 2002. Analytical expressions for transient specific yield and shallow water table drainage. Water Resources Research 38: 1193. DOI:10.1029/2001wr001071.

Nachabe M, Shah N, Ross M, Vomacka J. 2005. Evapotranspiration of two vegetation covers in a shallow water table environment. Soil Science Society of America Journal 69: 492-499. 
Orellana F, Verma P, Loheide SP II, Daly E. 2012. Monitoring and modeling water-vegetation interactions in groundwater-dependent ecosystems. Reviews of Geophysics 50RG3003:.DOI:10.1029/ $2011 \mathrm{rg} 000383$.

Qong M, Takamura H, Hudaberdi M. 2002. Formation and internal structure of Tamarix cones in the Taklimakan Desert. Journal of Arid Environments 50: 81-97. DOI:10.1006/jare.2001.0829.

Ridolfi L, D'Odorico P, Laio F, Tamea S, Rodriguez-Iturbe I. 2008. Coupled stochastic dynamics of water table and soil moisture in bare soil conditions. Water Resources Research 44W01435: . DOI:10.1029/ 2007wr006707.

Rushton B. 1996. Hydrologic budget for a freshwater marsh in Florida. Water Resources Bulletin 32: 13-21.

Scanlon BR, Healy RW, Cook PG. 2002. Choosing appropriate techniques for quantifying groundwater recharge. Hydrogeology Journal 10: 18-39. DOI:10.1007/s10040-001-0176-2.

Soylu ME, Lenters JD, Istanbulluoglu E, Loheide SP, II. 2012. On evapotranspiration and shallow groundwater fluctuations: a Fourierbased improvement to the White method. Water Resources Research 48: W06506. DOI: 10.1029/2011wr010964.

Tao H, Gemmer M, Song YD, Jiang T. 2008. Ecohydrological responses on water diversion in the lower reaches of the Tarim River, China Water Resources Research 44W08422: . DOI:10.1029/2007wr006186.

Vervoort RW, van der Zee SEATM. 2009. Stochastic soil water dynamics of phreatophyte vegetation with dimorphic root systems. Water Resources Research 45W10439: . DOI:10.1029/2008wr007245.

Wang P, Pozdniakov SP. 2014. A statistical approach to estimating evapotranspiration from diurnal groundwater level fluctuations. Water Resources Research 50: 2276-2292. DOI:10.1002/ 2013WR014251.

White WN. 1932. Method of estimating groundwater supplies based on discharge by plants and evaporation from soil - Results of Investigation in Escalante Valley. Tech. Rep., Utah - US Geological Survey. Water Supply Paper 659-A.
Willmott CJ, Ackleson SG, Davis RE, Feddema JJ, Klink KM, Legates DR, Odonnell J, Rowe CM. 1985. Statistics for the evaluation and comparison of models. Journal of Geophysical Research-Oceans 90: 8995-9005. DOI:10.1029/Jc090ic05p08995.

Wohlfahrt G, Haslwanter A, Hortnagl L, Jasoni RL, Fenstermaker LF, Arnone JA, Hammerle A. 2009. On the consequences of the energy imbalance for calculating surface conductance to water vapour. Agricultural and Forest Meteorology 149: 1556-1559.

$\mathrm{Xu}$ GQ, Li Y, Xu H. 2011. Seasonal variation in plant hydraulic traits of two co-occurring desert shrubs, Tamarix ramosissima and Haloxylon ammodendron, with different rooting patterns. Ecological Research 26: 1071-1080. DOI: 10.1007/s11284-011-0858-8.

$\mathrm{Xu} \mathrm{H,} \mathrm{Li} \mathrm{Y.} \mathrm{2006.} \mathrm{Water-use} \mathrm{strategy} \mathrm{of} \mathrm{three} \mathrm{central} \mathrm{Asian} \mathrm{desert} \mathrm{shrubs}$ and their responses to rain pulse events. Plant and Soil 285: 5-17.

Ye ZX, Chen YN, Li WH, Yan Y, Wan JH. 2009. Groundwater fluctuations induced by ecological water conveyance in the lower Tarim River, Xinjiang, China. Journal of Arid Environments 73: 726-732. DOI:10.1016/j.jaridenv.2009.01.016.

Yin L, Zhou Y, Ge S, Wen D, Zhang E, Dong J. 2013. Comparison and modification of methods for estimating evapotranspiration using diurnal groundwater level fluctuations in arid and semiarid regions. Journal of Hydrology 496: 9-16. DOI:10.1016/j.jhydrol.2013.05.016.

Yuan G, Luo Y, Shao M, Zhang P, Zhu X. 2015. Evapotranspiration and its main controlling mechanism over the desert riparian forests in the lower Tarim River Basin. Science China Earth Sciences 58: DOI:10.1007/s11430-014-5045-7.

Yuan G, Zhang P, Shao M-a, Luo Y, Zhu X. 2014. Energy and water exchanges over a riparian Tamarix spp. stand in the lower Tarim River basin under a hyper-arid climate. Agricultural and Forest Meteorology 194: 144-154. DOI: 10.1016/j.agrformet.2014.04.004.

Zhu JT, Young M, Healey J, Jasoni R, Osterberg J. 2011. Interference of river level changes on riparian zone evapotranspiration estimates from diurnal groundwater level fluctuations. Journal of Hydrology 403: 381-389. DOI:10.1016/j.jhydrol.2011.04.016. 